Article

\title{
Between Buddhism and Science, Between Mind and Body
}

\section{Geoffrey Samuel ${ }^{1,2}$}

1 School of History, Archaeology and Religion, John Percival Building, Cardiff University, Colum Drive, Cardiff CF10 3EU, UK; E-Mail: SamuelG@cardiff.ac.uk

2 School of Indian Sub-continental Studies, University of Sydney, NSW 2006, Australia

Received: 4 May 2014; in revised form: 2 July 2014 / Accepted: 7 July 2014 /

Published: 16 July 2014

\begin{abstract}
Buddhism has been seen, at least since the Theravāda reform movements of the late nineteenth and early twentieth centuries, as particularly compatible with Western science. The recent explosion of Mindfulness therapies have strengthened this perception. However, the 'Buddhism' which is being brought into relation with science in the context of the Mindfulness movement has already undergone extensive rewriting under modernist influences, and many of the more critical aspects of Buddhist thought and practice are dismissed or ignored. The Mind and Life Institute encounters, under the patronage of His Holiness the Dalai Lama, present a different kind of dialogue, in which a Tibetan Buddhism which is only beginning to undergo modernist rewriting confronts Western scientists and scholars on more equal terms. However, is the highly sophisticated but radically other world of Tantric thought really compatible with contemporary science? In this article I look at problem areas within the dialogue, and suggest that genuine progress is most likely to come if we recognise the differences between Buddhist thought and contemporary science, and take them as an opportunity to rethink scientific assumptions.
\end{abstract}

Keywords: Buddhism; science; Mind and Life Institute; Tantra; consciousness

\section{Introduction}

The initial context in which people in the West came to think of Buddhism as a rational philosophy with a high degree of compatibility with modern science was quite specific. It was an alliance between Buddhist reformers, based initially in Sri Lanka, and Western scholars and Buddhist sympathisers, from Europe and North America. 
The Sinhalese Buddhist reformers were essentially engaged in a struggle against colonialism. An important part of that struggle involved establishing the right of Buddhist thought to be taken seriously, on a par with Western modes of thinking, and if possible as superior to them. The reformers aimed to reverse the routine European dismissal of Asian thought as fanciful, inconsistent, based on myth and story and without real intellectual substance.

Here the encounter with Christianity, in the form of the missionary presence in Sri Lanka, was a key component. The Buddhist monks and scholars who argued against Christianity in a series of major debates, of which the most famous was that at Panadura in 1862, claimed that it was not Buddhism but Christianity that was fanciful, inconsistent, without real intellectual substance, and based on implausible myths and stories. The key speaker at Panadura was the monk-scholar Migettuwatte Gunananda. He and his colleagues argued that Buddhism, with its history of rigorous philosophical thought and its lack of an omnipotent, judgment-dispensing creator-god, had far more in common with science, which was emerging in the European context as a highly effective rival to Christianity, than with Christianity. Indeed, they suggested that Buddhism was barely a religion at all in the Western sense, but a scientifically-based philosophy in its own right. As for the Western scholars and sympathisers, many of them perhaps escapees from oppressive or conflicted Christian backgrounds, they were happy to collaborate in an enterprise which promised both to relativise the Church's claims to authority and to provide a new, more acceptable moral basis for contemporary life [1-3].

All this involved a certain amount of side-stepping of problematic issues. Buddhist sūtras might be dismissive of the claims of a creator-god, but they had plenty of gods, spirits, and miracles, while the Buddha himself was clearly regarded by most Buddhists as far more than an ordinary human being. If part of the problem with the Christian Church was the clergy, and their claims to authority, Buddhist monks also constituted a clergy, with many of the same problematic features. But this all got fudged in various ways, and in the process (I simplify a little) a highly authoritative and dominant new version of Theravāda Buddhism ${ }^{1}$ was created, to serve as a suitable dialogue-partner for a Western science which saw itself as empiricist and experimental, and which was only beginning to break away from the structures of Newtonian physics into the heady realms of relativity theory and quantum mechanics. This was a science confident that all the basic problems had been solved, and that what was left was to tidy up the details, and Theravāda Buddhism was positioned by its proponents, Asian and Western, as both confirmed by and confirming that confidence.

Thus Theravāda Buddhist intellectuals, above all in Sri Lanka, came to see themselves as bearers of a supremely rational tradition, compatible with science in all significant respects. The more obviously theistic and religious aspects of Buddhism were dismissed as folk superstition, or as resulting from contamination by Mahāyāna traditions, which were regarded as inauthentic, since not in accord with the Pali Canon. The development of lay meditation movements within Burma, Thailand and elsewhere in the early twentieth century reinforced this view of Buddhism as scientific philosophy rather than religion. The Buddhism which resulted was, one could say, pre-adapted for its incorporation in secularized

1 “Theravāda Buddhism" is a modern label for the dominant Buddhist school within Thailand, Myanmar, Cambodia, Laos and Sri Lanka. Contemporary Theravādin scholars generally claim that their school represents early Buddhism in pure form, and that other versions of Buddhist teachings are less authentic, resulting from later deviations and corruptions [4]. 
form into the Western therapeutic context a century later in forms such as Mindfulness-based Stress Reduction and Mindfulness-based Cognitive Therapy.

So far so familiar, perhaps. The point I am working towards, however, is that while the ways of thinking that derive from this initial alliance between Buddhist and Western scholars are still very much with us, the dialogue between Buddhism and science in which we are now engaged is quite different in nature. Neither the Buddhism, nor the science, has much in common with that which prevailed in this first major, and undoubtedly highly productive, encounter. If our predecessors, Asian and Western, could claim that Buddhism was a quasi-scientific set of ideas with a high degree of compatibility with Western science, this view of Buddhism as intrinsically 'scientific' has itself become a major obstacle to effective dialogue. I think this is one of the reasons why, despite there being plenty of activity taking place at present in relation to Buddhism and Science, it is rather hard to work out just what is being achieved. Many of the more interesting developments do not fit well into the familiar Buddhism and Science narrative, in which Buddhist knowledge is confirmed by a Western science that itself undergoes little or no change. Thus, while Mindfulness-based therapies and images of meditating monks undergoing brain scans have become almost over-familiar, suggesting a straightforward confirmation of Buddhist practice by Western science, the more significant developments are arguably elsewhere, in the potential of Buddhist thought to provoke genuine rethinking and transformation within science itself.

Perhaps the most widely-known and public context for contemporary debates in this area is that of the Mind and Life Institute dialogues presided over by His Holiness the Dalai Lama, and it is on these dialogues that I shall principally focus. ${ }^{2}$ These meetings between the Dalai Lama and Western scientists have been taking place now for around twenty-five years. The first meetings took place in 1987, and the most recent, in October and November 2013, was the twenty-seventh, on the subject of 'Craving, Desire and Addiction'. Initially, the meetings were mostly at Dharamsala in India, the Dalai Lama's residence in exile, but subsequent meetings have taken place at a variety of other locations in India and the USA. The participants have included a wide range of Western scientists, including physicists, psychologists, neuroscientists and biologists, as well as a number of Tibetan scholars. There have also been a number of additional associated conferences and other events, and a European branch of the Mind and Life Institute has also been created.

The Mind and Life Institute meetings are certainly much more eirenic and collaborative events than the late-nineteenth-century debates in Sri Lanka. In the Mind and Life Institute meetings, there is no longer a need for Gunananda's forceful claim for Buddhism to be taken seriously in the face of the supposedly authoritative claims of Western missionaries ${ }^{3}$. In contrast, we see a group of Western scientists engaged in a respectful discussion with a Buddhist spiritual leader, in which it is presumably taken for granted that what he might have to say in relation to their specialist fields is worthy of serious consideration. Of course, there are plenty of practicing scientists around today who would still be

\footnotetext{
Information on the Mind and Life Institute can be found at their website [5].

It would be interesting to know how far Gunananda was aware that the missionaries' own knowledge claims were becoming increasingly open to dispute back in the West. The Panadura debate took place four years after the publication of the first edition of Charles Darwin's On the Origin of Species in November 1859.
} 
dismissive of such dialogues, but the apparent level of acceptance of Buddhist thought within the wider field of Western science, compared to even twenty or thirty years ago, is striking.

We might, if we so chose, see the Mind and Life dialogues as a later point in an ongoing progression through which Westerners came to take Buddhist concepts and understandings more and more seriously as a system of knowledge with genuine claims to scientific value. A fairly smooth narrative could be constructed by which to link these two moments in time, involving as intermediary points perhaps the interest in Buddhism and in other Asian philosophical traditions from the 1920s onwards by physicists such as Wolfgang Pauli, psychoanalytic thinkers such as Carl Jung and Erich Fromm, and a variety of other significant figures in Western thought. The Buddhist influence on ecological thought in the West, through figures such as Gary Snyder and Joanna Macy, might also be drawn into this overall story [6].

Whether such a picture would look as plausible in another one and a half centuries, when the Mindfulness ${ }^{4}$ movement and the Mind and Life Institute will be as far in the past as the Panadura debate is today, is another question. Perhaps, rather than congratulating ourselves on the smooth onward progress of the collaboration between Buddhism and science, it is worth looking at some of the associated blockages and problems, and attempting to evaluate the actual nature of the dialogue in its current forms. To begin such an examination, I return to the Dalai Lama's Mind and Life dialogues, and in particular to a book published by the Dalai Lama in 2005. This book, which bore the provocative title The Universe in a Single Atom: the Convergence of Science and Spirituality, was a kind of programmatic statement for the Mind and Life project, presenting the Dalai Lama's views on the relationship between Buddhist thought and Western science [7]. The 14th Mind and Life debate, in Dharamsala in April 2007, was specifically devoted to the discussion of the Dalai Lama's book.

I should emphasise here that I have great respect for the Dalai Lama as a spiritual and political figure who has led the Tibetan people through an extraordinary difficult period in its history. I have no doubt too that his interest in science is genuine. The Mind and Life dialogues have now been going on for some twenty-five years. However, looking at the dialogues, particularly as they were around the time of the Universe in a Single Atom debate, it can seem as if there is a limited potential here for generating a real encounter between Buddhism and contemporary science. Much of the time, participants appear to be talking past each other, rather than to each other, in part perhaps because of communication difficulties stemming from translation issues, but also I think because of a mutual incompatibility of assumptions in some critical areas.

Consider a book review by Richard Davidson of the The Universe in a Single Atom, written shortly after its appearance in 2005 [8]. As I mentioned, the Dalai Lama's book constitutes a kind of manifesto for the whole Mind and Life Institute enterprise ${ }^{5}$. Richard Davidson is a highly-respected American neuroscientist who was at the time more or less in charge of the scientific side of the Mind and Life

4 I capitalise Mindfulness here and elsewhere to emphasise that 'mindfulness' in the context of the Mindfulness movement represents a particular understanding of the relevant Buddhist term, and a set of specific practices deriving from this understanding.

5 The Dalai Lama's many books are clearly for the most part collaborative works, and it is often difficult to work out how much in them represents his actual words, and how much is due to his various collaborators. The Universe in a Single Atom was clearly intended as an important statement, however, and I assume that the central statements in the book were, minimally, approved by him. 
Institute. However, faced with the Dalai Lama's assertion in his book of the evidence for continuity of consciousness between lives ${ }^{6}$ in the form of children's memories of past lives, Davidson clearly had trouble either accepting or rejecting the Dalai Lama's position.

The Dalai Lama had used this argument to establish that consciousness could exist separately from the body, and so to counter the materialist reduction that is the default assumption in much contemporary science:

The view that all mental processes are necessarily physical processes is a metaphysical assumption, not a scientific fact. I feel that, in the spirit of scientific inquiry, it is critical that we allow the question to remain open, and not conflate our assumptions with empirical fact ([7], p. 128).

From the point of view of the philosophy of science, the Dalai Lama's position here sounds reasonable enough. The view that all mental processes are necessarily physical processes is indeed not a scientific fact, it is simply a widely-shared foundational assumption among many, though by not necessarily all, communities of modern scientists [9]. But of course this materialist reduction forms a central part of the worldview of many, probably most, modern scientists. This is particularly true in fields such as neuroscience, Davidson's own specialty, which are heavily committed to a basically empiricist methodology in which experiments are held to reveal facts in a fairly straightforward way.

Davidson seems to have been caught in a cleft stick, between his respect for the Dalai Lama, and his awareness that appearing to take the Dalai Lama's suggestion seriously might cause a significant loss to his own scientific credibility. This is what he writes:

Needless to say, this is an extraordinarily controversial claim and one that most modern psychologists and virtually all neuroscientists would reject. Nonetheless, the Dalai Lama provides anecdotal examples that at least at face value appear to pose difficulties for the standard account of the material basis of mind. However, these kinds of claims have never been subjected to rigorous scientific scrutiny and need to be to effectively resolve this challenge [8].

Davidson strikingly fails to explain what these 'anecdotal examples' are. The principal one, in the Dalai Lama's words, is as follows:

I know of a remarkable case of a young girl from Kanpur in the Indian state of Uttar Pradesh in the early 1970s. Although initially her parents dismissed the girl's descriptions of a second set of parents in a place she described specifically, the girl's accounts were so concrete that they began to take her seriously. When the two whom she claimed to be her parents during her previous life came to see her, she told them very specific details of their deceased child's life, which only a close member of the family could have known. As a

6 Some authors make a distinction between "rebirth", implying the continuity of karma and/or consciousness (vijñ̄ana) from one life to the next, and "reincarnation", involving the continuity of personality and personal identity, and a reader of an earlier form of this paper, in which I had used the term "rebirth", questioned which was intended here. I avoid using either term in this version since it is not clear to me how far the memories of previous lives referred to by the Dalai Lama were intended to imply a total continuity of personal identity in a strong sense. Certainly this was not the key issue in his argument. 
result, when I met her, the other two parents had already fully embraced her as a member of their family ([7], p. 128).

Of course the Dalai Lama himself was, in theory at least, also someone who had retained memories from a previous life in his childhood, although he tends to avoid or downplay this particular issue when it is raised. His identification as the fourteenth Dalai Lama was based in part precisely on his ability to identify people and objects from a previous life ${ }^{7}$.

In fact, Tibetans can be quite cynical about the recognition of reincarnate lamas, which have often been highly political decisions, in which considerations quite other than the plausibility of the child's memories may enter ${ }^{8}$. However, for those who might wish to dismiss His Holiness's argument out of hand, early childhood memories of apparently previous lives are not just something that happen in a few exotic locations such as Tibet, or in a small number of isolated cases. There is quite a lot of material of this kind in the published literature by now, and some at least of it has arguably been subjected to a fair degree of "rigorous scientific scrutiny" [12,13]. Such evidence does not necessarily imply the validity of a Buddhist-type theory of rebirth, but it certainly provides support for the Dalai Lama's contention that consciousness can exist separately from the body. What is striking, though, is how difficult it is for someone who was for many years a central scientific participant in the Mind and Life Institute dialogues even to consider a basic element of the Buddhist world-view, the existence of consciousness separately from a material basis. Davidson continues in his review:

It should be noted, though, that certain scientific assumptions are themselves based on well-established principles that have been subjected to lengthy empirical validation, and thus it is not necessary, nor is it realistic, to test every empirical possibility. Some would say that the dependence of mind on brain is one such assumption that has been subjected to countless empirical tests, and each and every one of them has provided support for this general claim. At what point are global generalizations then reasonable [8]?

The 'Some would say' in this passage is notable; Davidson neatly avoids either affirming or denying the statement that follows, but it is hard to believe that he was completely unaware of the existence of substantial evidence that might be held to contradict it.

My point here is not a personal one about Davidson himself, whose personal views at the time may well have been more complex than he felt he could admit in the pages of PsycCRITIQUES, an official organ of the American Psychological Association. It is rather that this exchange points to the nature of boundary-maintenance within contemporary scientific disciplines, and the way in which this is maintained by openly or tacitly ruling certain kinds of evidence out of consideration. Scientific theories, however established, are not the theories that account most effectively for the available

7 The Tibetan understanding of yang srid, or 'reincarnate lamas' as they are commonly known in English, is in some respects distinct from that of spontaneous memories such as those of the young girl from Kanpur, since it also involves an ideology of the deceased lama's deliberate return through Tantric control of consciousness during the period between lives ([10], pp. 281-86, 493-98).

8 This was arguably the case for His Holiness the Dalai Lama himself, if Matthias Hermanns' contemporary account is to be believed, although the ambiguities present at the time were largely written out of subsequent retellings of the story ([11], vol. 3, 123ff). 
evidence, but, at best, those that account most acceptably for the evidence ruled as relevant and admissible within a particular discipline or subdiscipline. Their reality is as much social as intellectual.

All this is not to deny that there is a real problem about how to make scientific sense of Buddhist ideas about the continuity of consciousness between successive lives. The late Francisco Varela, a central figure in the creation of the Mind and Life Institute dialogues, and a key participant in the earlier dialogues, gave his own perspective on the issue in an interview made in 2000, shortly before his death:

So [the Tibetans] have this notion which people call "reincarnation"- - I think that that's a very bad translation [...]. To my understanding, the interesting view there is this kind of idea of flow of consciousness, which has moments in which it manifests as a more layered consciousness, including mental phenomena and cognition, and then after death it continues like a flow and it comes up again. But there would be, then, according to their observations such a thing as a form of consciousness, although not individual consciousness, not a "me-consciousness", but a consciousness, in other words, an awareness that is aware of itself, without brain. Now that is a little hard to swallow for a scientist. We have had this conversation several times with His Holiness and at that point we both say, well, what to say? At this point, science cannot even conceive of that, cannot possibly deal with that idea, and in the Tibetan tradition it is inconceivable not to take into account their accumulated experience and observation that this is so. Including accounts, and witness accounts, and what not. And my position is, Suspend judgment. Don't say it's false, don't say it's true, don't neglect their observations, don't simply say, oh science is so stupid, you know. Let's go gentle, let this be a question. And as oftentimes, I've learned in my life that one of the greatest difficulties is to have the patience and the forbearance to actually stay with the open question, and not to seek for resolution or an answer, just to contemplate the question and let it sit there, which is not easy, but that's the way to go 9 .

Varela's own cross-disciplinary perspective, grounded in biology, philosophy, and evolutionary theory, as well as a deep personal engagement with Buddhist practice, arguably offered more scope for a genuine dialogue with Tibetan Buddhist thought than the reductionist versions of neuroscience implied by Davidson's "Some would say..." For Varela and his associates, consciousness was something that emerged and took place as part of an interactive and multidimensional field, within which the individual brains was only one component (e.g., [16]). I shall return to the work of Varela and his co-workers later, since it seems to me to represent one of the most promising aspects of the current dialogue between Buddhism and science.

If the question of consciousness and the brain is a particularly difficult one, it is not the only place where interchanges between science and Buddhism are less straightforward and transparent than they may seem to an outsider. One which has received a fair amount of attention already has been that of the so-called Mindfulness movement, arguably based, for the most part, on a secularised and simplified

9 This passage can be found in Franz Reichle's film Monte Grande: Francisco Varela (T\&C Film AG, 2005, released in the USA by First Run/Icarus Films), beginning about 61 minutes into the film [14]. The transcription is my own. A brief account of Varela's personal history and his involvement with Buddhist practice is given in another Mind and Life-derived volume ([15], pp. 306-10). 
version of contemporary lay Burmese vipassanā practice. Mindfulness-based therapies have been widely adopted in clinical psychology, psychiatry, and related fields, as well as being popularised as a more generalised self-help modality in the wider community. We are still in the early stages of evaluating where these therapies are genuinely useful. It seems likely that they are making a positive contribution in many areas, if only as a replacement for the widespread use of drug therapies with risky side-effects. Arguably, however, this use of Buddhist-derived practice as therapy, as a way of adjustment to life in the everyday world of samsāra, is in direct contradiction to the orientation of the Pāli Canon and of the Nikāya period of early Buddhism, from which these practices are often claimed to derive ${ }^{10}$. The Buddhism of this period emphasised withdrawal from the everyday world of samsāra, not adjustment to it $[17,18]$.

A similar issue arises in relation to the discussion of 'destructive emotions,' which has been a major theme in a number of Mind and Life dialogues as well as the basis of several popular books (e.g., [15]). "Destructive emotion" implies that there may also be positive and constructive emotions, and it is a generally-shared assumption of most contemporary Western societies ${ }^{11}$ that this is the case. Yet "destructive emotion" corresponds to the Sanskrit kleśa, often translated as "mental obscuration", "defilement" and "affliction". While some at least of the kleśa, which constitute in Buddhist thought the underlying driving mechanism for the suffering of samsāra, might in a generic sense be regarded as "emotions", there is no corresponding term for a "positive" or "constructive" counterpart. For the Buddhist tradition, all "emotion" is arguably negative ${ }^{12}$. Here, as in the case of the Mindfulness movement, a focus on the negative qualities of "destructive emotions" may well make for good therapy in a contemporary Western sense, but it arguably does so by removing Buddhist concepts from a context within which they are part of a consistent and meaningful understanding of the world and inserting them into another and very different context.

All this is in no way intended to invalidate the positive achievements of the Mind and Life Institute $^{13}$ and of the various attempts to apply Buddhist-derived tools for the improvement of contemporary society, but it does suggest that much of what happens in this process is less a dialogue

10 I use this rather clumsy circumlocution as a way to avoid the term Hīnayāna, with its pejorative implications, and Theravada, which is problematic and inaccurate as an exclusive label for "early Buddhism". It should be noted that material from this period can be found in all Buddhist traditions, as well as in surviving manuscripts from the early period.

11 "Contemporary Western societies" here is used as a shorthand expression for a dominant set of orientations within much of the contemporary world. These orientations are of course neither confined to historically "Western" (European, American, Pacific) contexts, nor universal within them.

12 The terms for the positive counterparts of the three principal kleśa (greed, hatred and delusion) simply refer to the absence of greed, hate and delusion. There is of course at least one positive motivational state within Buddhism, bodhicitta, the drive to achieve Buddhahood so as to relieve the sufferings of all sentient beings, particularly celebrated within the later "Mahāyāna" traditions, but it hardly corresponds to the contemporary understanding of emotion.

13 As far as the Mind and Life Institute is concerned, it should be noted that these dialogues have served a variety of other functions besides the interaction between Western scientists and Buddhism that form their principal public face. They, and particularly the books associated with the dialogues, have come to constitute a significant part of the presentation of Tibetan Buddhism to a new mass Western public. (Sales of some of these books are easily in the tens of thousands.) The Mind and Life Institute is also closely linked to another project in which the Dalai Lama has shown considerable interest, that of providing the new generation of Buddhist monks in the Tibetan tradition with a basic training in Western science. 
between equal systems of thought than an assimilation of the more "acceptable" elements within Tibetan and Buddhist thought into an essentially Western context of ideas. If this is what is going on, are we perhaps missing an opportunity for a fuller and more genuine dialogue?

\section{Neuroscience and Contemplative Science: The Stand-Off}

We can explain the limited nature of much of the present dialogue fairly simply. On the Western side, while there is certainly sympathy for aspects of the Buddhist tradition, most scholars are still working within established paradigms that allow little or no space for central assumptions of Buddhist thought. On the Buddhist side, the principal participants are no longer Westernised supporters of a simplified, demythologised Theravāda, but proponents of the much more complex, sophisticated and, importantly, largely unmodernised Tibetan tradition. The proponents of the Tibetan tradition neither desire nor need to concede much to Western modes of thought, particularly given the high profile of and level of public respect for the Dalai Lama himself. The Dalai Lama is undoubtedly a complex person who lives many different roles (including that of the simple Buddhist monk) in the service of the Tibetan people and of Tibetan Buddhism. An important part of his background, however, is that he is someone with a thorough and extensive training in the arguments and positions of Mahāyāna philosophy, as presented by the Gelugpa school, of which he is the leading proponent. He is a highly trained debater and logician who has learned to think within the categories of a school of thought which arguably offers a much deeper challenge to the assumptions of Western science than the rationalized Theravāda of the early twentieth century. And while the Dalai Lama is certainly interested in Western science, he does not, as we have seen from the quote before, start from the assumption that science is a final source of authoritative knowledge. It is difficult to be sure from the published versions of the dialogues how much the Dalai Lama actually understands of Western science, but it is pretty clear that he sees it as far from perfect, and as in need of change and revision.

Does he also see Buddhism in need of change and revision? The question of how much the Dalai Lama is a modernist, and how much a traditionalist, is quite hard to answer, beyond it being pretty obvious that there are both components in his make-up. In fact, the Dalai Lama has frequently emphasized the empirical and open nature of Buddhist thought:

[O]ne fundamental attitude shared by Buddhism and science is the commitment to deep searching for reality by empirical means and to be willing to discard accepted or long-held positions if our search finds that the truth is different ([7], p. 25).

He has even, famously, stated on many occasion that if science disproves Buddhist arguments, Buddhism will have to change. However this statement appears to refer in practice to relatively marginal issues. The Dalai Lama, in other words, is not interested in insisting on the literal truth of traditional Buddhist geography, according to which we live on the island continent of Jambudvīpa, in the middle of the southern ocean of a mandala-shaped universe centered upon the fabulous Mount Meru. However, as Rob Hogendoorn has argued, when it comes to more central matters, such as the nature of consciousness, the situation is rather different ${ }^{14}$. In practice, the Dalai Lama's position in

14 See his article in this special issue, "Caveat Emptor: The Dalai Lama's Proviso and the (Scientific) Burden of Proof" [19]. An earlier presentation of his perspective may be found at [20]. 
relation to these issues is effectively defended from the possibility of refutation, and it is quite hard to imagine any situation in which he might actually concede the need for fundamental change. On the Western side, scholars like Davidson represent a version of Western science that, while undoubtedly successful within its own terms, also often seems to have little real openness to change or encounter.

The relationship between meditation and neuroscience is a particularly significant area for these exchanges, both because of the currently high profile of neuroscience within Western society, and because this relationship raises the question of consciousness and its status in a particularly direct way. For neuroscience, Buddhist practices constitute a set of physical and mental processes that, hypothetically, bring about certain changes within the human organism, which can be detected through functional magnetic resonance imaging (fMRI) and similar techniques.

One can certainly scan the brains of Buddhist meditators and observe that something is going onconsider for example the images of the location of compassion in the brains of Buddhist meditators in a paper by Davidson's research group [21]_but as Jay Garfield noted a couple of years ago, this in and of itself is not surprising, since just about everything we do, from sleeping to watching television to riding a bicycle, has neural activity associated with it [22]. There are also any number of serious questions about what these brain scans, which are typically averages of a number of individuals and based on minute fluctuations of blood flow which are supposed to act as a proxy for brain activity, really tell us (e.g., [23-25]. In reality, we are some way from tracing neural activity in an individual brain in any detail, despite optimistic claims by some scientists to be doing just that.

Here again I am not intending to be dismissive of research on consciousness in neuroscience. It is certainly of genuine scientific interest to know how the neural activity of parts of the brain may be engaged by different kinds of activities. This might also have significant implications for Buddhist practice, for example in terms of biofeedback procedures of various kinds to aid learning meditation. It might also help to demonstrate the effectiveness of the various Buddhist-derived therapies, such as those which have developed within the Mindfulness movement. But Buddhist thought is not derivative from Buddhist practice or Buddhist experience in any simple way, and no amount of brain-scanning of meditating yogis will either prove or disprove Madhyamika philosophy.

What the research in neuroscience carried out by scholars such as Davidson and his colleagues seemed to be aiming at was that science would somehow confirm what the meditators are finding, on the one side, and that the findings of the meditators would somehow be incorporated as a complement to scientific knowledge, on the other. This was the position taken by Alan Wallace, another long-term participant in the Mind and Life Institute dialogues. According to Wallace, there is Western science, which gives external knowledge, and involves observations through mechanical measuring-instruments, and there is Asian thought, nowadays often repackaged under the new label of 'Contemplative Science,' which gives internal knowledge, and involves observations through human measuring instruments in the form of highly-trained yogic practitioners (e.g., [26,27]). Thus, both Western scientists and yogic practitioners are, at least in some ideal sense, undertaking an objective, empiricist process of fact-gathering, and one can simply add together what each side is doing. Meditation can be seen as a kind of 'internal empiricism', providing an important first-person complement to the thirdperson perspectives that dominate most Western scientific research, but equally objective in its methods and results. 
Arguably, this distorts the reality on both sides. Most critically, as we have noticed, both Buddhists and neuroscientists work from an established framework of assumptions, and those assumptions are, on the face of it at least, mutually exclusive. In addition, arguably, the role of meditation in the Buddhist tradition is not to investigate one's consciousness in an open-minded, exploratory way. It is to transform oneself so as to perceive the same fundamental insights that the Buddha himself and the great masters of the Buddhist tradition in the past were held to have seen, in the same way that the Buddha and his successors saw them [28].

It would be wrong to dismiss Wallace's approach out of hand. Yogic experience is certainly worth taking seriously, and Wallace has a useful and critical awareness of the limitations of Western science. It is not surprising, however, that this approach is yielding considerably less than might have been hoped. However, if the philosophical bases of the two traditions are essentially incompatible, is there any way forward?

\section{Moving the Debate Forward}

The purpose of the rest of this article is to argue that there is, or could be. Here I think it is useful to look at some of the contributions to the debate within and outside the Mind and Life Institute that have received less attention in recent years than the fMRI scans of meditating yogis and similarly high-tech projects.

It will also help if we start by pluralizing, and by loosening up, on both sides, Buddhist and scientific. On the Buddhist side, I have emphasized that one of the differences between the early twentieth century dialogue, which established - one might say-many of our default assumptions about Buddhism and science, and those at the Mind and Life Institute is that the Buddhism that is engaged is actually quite different. In fact, even within Tibetan Buddhism, there is a whole range of positions and approaches, and the Dalai Lama's Gelugpa scholasticism is only one of these.

In addition, as critical voices in religious studies have been pointing out for some time, terms such as Buddhism and Hinduism are already inherently problematic. These are Western terms, not indigenous terms, and they derive from a Western need to classify the rest of the world in Western categories, and an Asian willingness to accept the terms of that project [2]. The reduction of Buddhism to an empiricist project based around meditative experience has been particularly questioned; Robert Sharf's contributions in this area, which radically questioned the whole role of experience and meditation within Buddhism, are especially pertinent [29,30].

Sharf, in seeking to establish an important and valid point, perhaps took the argument a little too far. Meditation may not be anything like as central to Buddhist practice as Westerners typically assume, but it does take place, and it has played a significant historical role in the development of Buddhist philosophy and practice. It may be true that, as Andrew McGarrity has argued [28], experience in Buddhism is typically more concerned with validating and confirming knowledge established on other grounds than on constituting a source of knowledge in its own right ${ }^{15}$. More

15 Wallace is aware of the problem here, but evades it. For Wallace, both science and religion began with experience, and are declining into fundamentalism. Wallace is certainly aware that most scientists take most of science on faith and for granted, and that most Buddhists do not meditate and take Buddhist doctrine equally for granted, but his imagined histories of science and religion postulate some earlier stage when things were different ([26], pp. 185-86). 
exploratory and creative approaches to experience can however also be found. The ongoing transformations of Nyingma Buddhism in Tibet through the visionary experience of the tertön or treasure-finders would seem to provide at least one reasonably convincing example ([10], pp. 294-302, pp. 461-63; [31,32]).

If Buddhism is not essentially a body of empirical knowledge derived from yogic insight, however, and if the core of the Buddhist tradition is really a different kind of enterprise altogether, then we can no longer assume the simple complementarity of Western Mechanistic Science and Asian Contemplative Science argued by Wallace and others. In any case, we have little reason to assume that yogic perception is the perfect inner measuring instrument that Wallace suggests; as Garfield noted in the article I referred to above, yogic observation appears to have missed, for example, a whole series of basic physiological aspects of optics [22].

If we turn to Western science, critical voices have also been around for a while, and the naïve empiricism and reductive materialism that is the default position for much modern science, including most neuroscience, really a hangover from the Newtonian science of the nineteenth century, has been contested from a variety of quarters. A whole series of significant thinkers in the philosophy of science (Karl Popper, Imre Lakatos, Thomas Kuhn), sociology of knowledge (Michael Mulkay, David Bloor), and more recently the emerging field of science and technology studies (Bruno Latour, Donna Haraway, Emily Martin) have complicated the picture in interesting and significant ways ${ }^{16}$. These often quite varied thinkers and arguments do not add up to a single unified position, but they certainly all contribute to a picture of scientific knowledge as both various, and deeply invested with background assumptions of different kinds.

As an anthropologist, the way I would put it is that Western science is a part of culture, and that despite the famous claims of objectivity and value-freedom made on its behalf, all modes of scientific enquiry are deeply shaped and formed by the personal lives of the researchers, and by their social and cultural contexts. This affects fundamental issues such as what questions are asked by particular sub-fields within science, what connections are regarded as plausible bases for scientific hypotheses, what methodologies are adopted to investigate them, and what data are seen as relevant or as irrelevant. These issues are all entangled with other more directly politically and economic questions: what research is funded and supported, and who gets to be in the positions where such decisions are made. Neither this, nor the widespread practice of deliberate fraud and of the massive skewing of results by selective suppression of evidence in areas such as pharmaceutical research [38,39], invalidates scientific knowledge, which has of course demonstrated its utility and its human value in many areas. The issues mentioned do however suggest considerable caution in taking any particular set of scientific results as final or established They also suggest that what we have in any particular subfield of Western science is only one of a whole series of possible alternative bodies of scientific knowledge, and that some of the others might be quite different, and, perhaps, equally or more valid and efficacious, if in different ways [32,39,40].

16 For Popper, Lakatos, Kuhn, and Mulkay, see e.g., ([33], pp. 17-22, pp. 34-35). For the other authors mentioned, see e.g., [34-37]. 


\section{The Problem of the Self}

All this allows us to treat both sides in the debate as more fluid and as more situated in the ongoing lives, and the social and cultural contexts, of the participants. What this does, I suggest, is to create an intermediate space in which a more realistic dialogue is possible. However that statement assumes something about what a 'realistic dialogue' might be. Personally, I would like both a more provisional, tentative, playful, and genuinely experimental, approach on both sides. I also feel that what we might call traditional Asian thought has genuine potential for critical revision and extension of Western science. In 'traditional Asian thought' I would include not only the various Buddhist traditions, but also the very substantial material on related ideas within the Śaiva and Vaișnava traditions of South Asia [42,43], and in the Chinese traditions of Daoist practice [44].

One critical issue that has been ignored within much of the current scientific work on neuroscience, meditation, and Mindfulness might provide an important starting point for such revision and extension. This is the question of the self, of personal identity, and of the relationship between the individual and the wider universe. This is a key concern within Buddhist thought, and in somewhat different ways it has also been a key concern for Hindu and Daoist thinkers, who have their own ways of relativising the ordinary self in relation to more inclusive and interconnected conceptualisations.

Here is where I find some basic problems with the more conventional versions of the neuroscientific studies of Buddhism. Neuroscience is essentially a study of brains - individual brains. Now, at some level, anyone who has had any serious involvement with Buddhist thought knows that there is a problem for Buddhism in treating individuals as isolates (much the same is true on the Hindu side, but my central theme here is Buddhism, so I will focus primarily on the Buddhists). Whatever Buddhahood might be, it evidently involves a thoroughgoing awareness of radical interdependence. However, as human beings who have learned to think of ourselves as individuals, and particularly as citizens of a Western, and increasingly global, civilization in which the autonomous individual human being is a basic datum of our experience, it is very difficult not to take the separateness of the individual for granted in all kinds of ways. I have suggested elsewhere that the same issue can easily surface in relation to modernist styles of meditation, and to the Mindfulness-based therapies that derive from them [18]. Here the ecological and 'enactive' approach to consciousness developed by Varela, Thompson, Rosch, and others arguably provides much more substantial and plausible ground for productive interface with Buddhism and other Asian traditions of thought than the empiricist and individualistic assumptions of much neuroscience and cognitive science [16]. Varela, Thompson and Rosch's work, developed on the basis of Varela's earlier work with Humberto Maturana, his mentor at the University of Chile, and that of other ecologically-oriented thinkers such as the late Gregory Bateson [45,46], and later extended by Thompson and others (e.g., [47]), sees cognition, and cosnciousness in general, as part of an ongoing process in which both 'world' and 'mind' are constituted through mutual interaction. Such an approach allows for a variety of different kinds of "consciousness", which do not have to be understood simply as a by-product of neuronal activity within the brain.

It is, I think, interesting and significant that the question of the situatedness of cognition and consciousness occurs over and over again in the critical literature within and about work in 
neuroscience, though expressed in a variety of often quite different ways. Take the British sociologist of science Steven Rose, for example, in a paper called. "The Need for a Critical Neuroscience":

The truth is that in order to approach consciousness as a neuroscientist, one first has to strip the term of any of its richer meanings. It isn't just Freudian consciousness with its contrasting subconscious that goes, but also Marxian class consciousness, feminist consciousness and race consciousness. As feminist sociologist of science Hilary Rose has pointed out [. . .], consciousness in this neuroscientific sense has been taken out of history and culture; there is no possibility of understanding the extraordinary transitions in consciousness that have occurred through, for instance, the emergence of the women's movement in the 1970s. Instead, consciousness is simply what happens when you are awake, the obverse of being asleep. [ . .T]he essential human meanings embedded in our being conscious have somehow been lost in this reduction ([48], pp. 58-59).

Rose proceeds to present what he calls the 'autopoetic view,' in which consciousness evolved as part of culture, driven by the social nature of human existence, and refers to the development of a whole new field of "social neuroscience", stimulated by the discovery of so-called "mirror neurons" ([48], p. 59). "Autopoesis" here is a direct reference to Varela's work with Maturana [45]. But the central issue here is the huge limitation involved in the materialist reduction.

Notice that while Rose is not talking about karma and rebirth, he $i s$ arguing for consciousness as something that exists 'outside' the human body. It is perhaps worth noting too the linkage with feminist consciousness in this quote-Rose cites his wife, the feminist sociologist Hilary Rose in this passage. Historically, feminist thought has been at the forefront of the critique of the focus on the "isolated human individual", in large part, of course, because, historically, women have suffered disproportionately as a result of that particular cultural emphasis.

The medical anthropologist Emily Martin, best known for her pioneering early work in the feminist critique of science, makes similar points in an article entitled "Talking Back to Neuroreductionism", which takes on both neuroscience and parallel developments in cognitive science [49]. Martin points out the rhetorical strategies used by the reductionists to marginalize alternative views, including the assertion that their critics are stuck in ignorant, typically female modes of thinking:

In other words, the Churchlands [who take a reductionist position] are with the "men" over there in the neurophysiology lab developing dynamic, powerful, explanatory, hard, rational truth; Searle and Putnam [who resist reductionism] are over here with the "girls" in the kitchen, stuck in modes of thought that are rigid, inept, sloppy, soft, irrational and false ([49], p. 201).

Ironically, as she goes on to note, "transcendental reason, the prototype of masculine, abstract thinking, has indeed been dislodged from its eminent position, and the body, prototype of feminine concrete existence, has risen to take its place. But this "body" is universal, unhistorical [and] unconscious of its own production" ([49], p. 202) and in fact the body-centred approach of the neuroscientists and cognitive scientists replicates the characteristics of the modernist scientific accounts that the feminist theorists and other critical scholars on science had earlier attacked. Again, a 
key feature of Martin's critique is the way in which history and culture have been excluded from any understanding of consciousness.

For Martin, Rose, and many others, key aspects of consciousness, and so also key aspects of the self as we experience it, cannot be separated from their wider social, historical and ecological context. It may be noticed that this brings us much closer to Buddhist senses of our experience of the world as fundamentally constructed through mutual causation (pratītya-samutpāda, 'dependent origination' in Buddhist terminology). I am not suggesting that the Buddha, or pre-modern Tibetan thinkers for that matter, would necessarily have recognised the concerns with class, gender or ecology that underlie Rose or Martin's critiques, but those contemporary concerns have generated an awareness of the situatedness of consciousness which offers much more scope for productive interaction with Buddhist thought than the perspective of the 'neuroreductionists' against whom they are arguing.

The philosopher Bill Waldron is another participant in the Mind and Life dialogues who has taken up a similar position, and it is worth referring here to his "Buddhist Steps to an Ecology of Mind: Thinking about 'Thoughts without a Thinker"' [50]. This article uses the principle of pratitya-samutpāda or dependent origination, one of the most basic and central elements of Buddhist thought, to argue for a position in which consciousness, and specifically our consciousness of ourselves as separate individuals, arises through the ongoing network of connections between human beings and the wider environment. Waldron's title here is an explicit homage to Bateson, who features at length in the argument, as do Maturana and Varela, as well as Fritjof Capra and others. I shall not attempt to summarise the article, which is something of a tour de force in its systematic rewriting of basic Buddhist concepts in a Batesonian framework. The focus is less on culture on general than on language as the key place where categorisations, classifications and cultural understandings are stored:

languages are like habitats, because they give rise to the inexhaustibly proliferating processes (prapañca) of classification and conceptualization (vikalpa) through which we habitually, nearly unavoidably and mostly unknowingly engage, construct and perpetuate the "world" which simultaneously sustains and ensnares us ([50], p. 48).

For me, the emphasis on language, perhaps motivated by Waldron's desire to keep his analytic framework as close as possible to the traditional Buddhist categories, goes a little too far. The general point though is that we are beginning to develop a range of approaches that have in common a use of wider contexts - culture, language, history, ecology - to map a model of consciousness that is not purely local and certainly not reducible to the pattern of neuronal or chemical activity within an individual brain. Varela himself, in a late paper written with Natalie Depraz and included in a Mind and Life Institute dialogue volume Buddhism and Science: Breaking New Ground, edited by Alan Wallace, argued that the upwards causation of conventional neuroscience, in which consciousness is seen as derivative of the body, needs to be complemented by a downwards causation from the emergent structures of the self, which develop within the neural system as part of the process of maturation of each human being [51].

I have explored similar approaches in my own work over the years, initially when trying to understand deity yoga in Tibetan Tantric meditation, and more recently when looking at Tibetan medicine and Tibetan health practices. I will not go into detail about these analyses here, since I have written about them at length elsewhere, but they have focused on describing and analyzing the 
conceptual space that emerges once we drop the rigid dichotomies between body and mind and between self and environment (see in particular [33]). Consider, for example, those Tibetan Tantric practices that involve imaginatively-created models of the wider universe, in which the practitioner becomes a deity, or a male-female deity couple, at the centre of a Tantric mandala. This is a quite different kind of Buddhist practice to that which forms the basis of therapeutic techniques such as Mindfulness-Based Stress Reduction, and it presents, at least on the surface, much more of a challenge to Western conceptions of the universe (see e.g., [18]). Opening up the space between self and environment, however, in the way that Varela, Thompson, Rosch and others have done, allows one to see such a process as a meaningful operation on the 'ecology of mind,' with plausible effects on the individuals that inhabit that ecology.

Thus the Chimé Sogthig practices for long life and health, which I studied as part of a research project with Cathy Cantwell, Rob Mayer, Lopon Orgyan Tandzin, and Lama Kunsang Dorje, from 2007 to 2010, involves the systematic internalisation of a view of the universe as a source of nourishment and support inhabited by benevolent Tantric deities. This process is repeated over and over again by practitioners undertaking the Chimé Sogthig in retreat contexts, with the aim is to build up a sense of oneself as the deity-couple at the centre of a mandala of benevolent, life-giving spiritual forces. One can easily see such a process as overriding or modifying the individual's more everyday view of the self as an isolated being in an environment that is a source of threat, loss and injury. The point is that the effects here do not have to be understood as restricted to the neural substrate of an isolated individual, but as rippling out through the people with whom the individual interacts, and the entire ecosystem within which consciousness is located [52-54].

My most recent exercise of this kind was a chapter in a book with Jay Johnston, Religion and the Subtle Body in Asia and the West [9]. What I tried to do there was to look at a component of Asian religious thought, both Buddhist and Hindu (there are also Chinese and Sufi parallels), which has historically been found most refractory to Western scientific understanding, the idea of a subtle body made up of cakras, channels and internal subtle flows, and to suggest that we can see it not as bad science but as an attempt to create a level of analysis intermediate between mind and body, appropriate perhaps to the emergent self in the Varela and Depraz account, or the enactive model more generally. I suggested that the subtle body, like the Tantric deity, is less a picture of what is than part of a process intended to bring about change within human consciousness ${ }^{17}$. From that point of view, it can be seen as a kind of map of the brain and central nervous system (and perhaps also of the associated flows within the endocrine system) as seen from the inside. Its point is not so much to describe, but, like the mandala, to aid in bringing about change ([9], pp. 262-63; see also [10], p. 237).

\section{Conclusions}

How plausible these particular conjectures might be is another question, and obviously I am only summarizing them very briefly in this article. What I think they point to, however, along with some of the other work I have been discussing, is the possibility of a level of analysis that stands in some

17 See also Hayes' similar suggestion [43]. I would add to Hayes' account that the transformation does not just take place within the individual, but, as suggested above, within the entire ecosystem within which consciousness is located. 
respect outside both traditional Buddhist language, and other related Asian conceptual frameworks, on the one hand, and the default assumptions of scientific materialism, on the other. The aim is to define a space within which we can explore what these Buddhist and other Asian bodies of thought might be talking about so as to enrich and extend Western scientific understandings, rather than simply reducing them in order to fit in with what we think we already know.

\section{Acknowledgements}

This is a revised version of a public lecture given as Keynote Lecture for Buddhism and Science Workshop which took place at the University of Toronto, Scarborough, 12-14 April 2014 as part of UTSC's Tung Lin Kok Yuen (東蓮覺苑) program.

\section{Conflicts of Interest}

The author declares no conflict of interest.

\section{References and Notes}

1. Gombrich, Richard, and Gananath Obeyesekere. Buddhism Transformed: Religious Change in Sri Lanka. Delhi: Motilal Banarsidass, 1990.

2. King, Richard. Orientalism and Religion: Post-Colonial Theory, India and the Mystic East. London: Routledge, 1999.

3. Harris, Elizabeth J. Theravāda Buddhism and the British Encounter: Religious, Missionary and Colonial Experience in Nineteenth Century Sri Lanka. London and New York: Routledge, 2006.

4. Skilling, Peter, Jason A. Carbine, Claudio Cicuzza, and Santi Pakdeekham, ed. How Theravāda is Theravāda? Exploring Buddhist Identities. Chiang Mai: Silkworm Books, 2012.

5. Mind and Life Institute. Available online: http://www.mindandlife.org/ (accessed on 8 July 2014).

6. Samuel, Geoffrey. "Buddhism and a Sustainable World: Some Reflections." Sydney Ideas Lecture, University of Sydney, 20 September 2010. Available online: http://sydney.edu.au/sydney_ideas/lectures/2010/professor_geoffrey_samuel.shtml (accessed on 3 May 2014).

7. His Holiness the Dalai Lama. The Universe in a Single Atom: The Convergence of Science and Spirituality. New York: Broadway Books, 2005.

8. Davidson, Richard. "Science and Spirituality: Probing the Convergences and the Tensions." PsycCRITIQUES 51, no. 28 (2006): 1-5. A review of The Universe in a Single Atom: The Convergence of Science and Spirituality by Holiness Dalai Lama. Available online: psyphz.psych.wisc.edu/web/pubs/2006/Davidson_Universe.pdf (accessed on 11 July 2014).

9. Samuel, Geoffrey. "Subtle-Body Processes: Towards a Non-Reductionist Understanding." In Religion and the Subtle Body in Asia and the West. Edited by Geoffrey Samuel and Jay Johnston. London and New York: Routledge and Kegan Paul, 2013, pp. 149-67.

10. Samuel, Geoffrey. Civilized Shamans: Buddhism in Tibetan Societies. Washington: Smithsonian Institution Press, 1993. 
11. Hermanns, Matthias. "Teil 3: Erlöser und Heilbringer der Tibeter." In SchamanenPseudoschamanen, Erlöser und Heilbringer: Eine vergleichende Studie religiöser Urphänomene. Wiesbaden: Franz Steiner, 1970. (In German)

12. Stevenson, Ian. Children Who Remember Previous Lives: A Question of Reincarnation, rev. ed. Jefferson: McFarland, 2001.

13. Kelly, Edward F., Emily Williams Kelly, Adam Crabtree, Alan Gauld, Michael Grosso, and Bruce Greyson. Irreducible Mind: Toward a Psychology for the 21st Century. Lanham: Rowman \& Littlefield, 2009.

14. Reichle, Franz. Monte Grande: Francisco Varela. T\&C Film AG, released in the USA by First Run/Icarus Films, 2005 [Film].

15. Destructive Emotions and How We Can Overcome Them: A Dialogue with the Dalai Lama, Paperback ed. Narrated by Daniel Goleman. London: Bloomsbury, 2004.

16. Varela, Francisco J., Evan Thompson, and Eleanor Rosch. The Embodied Mind: Cognitive Science and Human Experience. Cambridge, MA and London: The MIT Press, 1991.

17. Williams, J. Mark G., and Jon Kabat-Zinn, eds. "Special Issue on Mindfulness." Contemporary Buddhism 12 (2011): pp. 1-306.

18. Samuel, Geoffrey. "The relevance of non-self in pre-modern Asia and the contemporary mindfulness movement." Transcultural Psychiatry (2014), forthcoming.

19. Hogendoorn, Rob. "Caveat Emptor: The Dalai Lama's Proviso and the Burden of (Scientific) Proof." Religions 5 (2014): 522-59.

20. Hogendoorn, Rob. "Probing Mind and Life." Lecture for the Columbia Society for Comparative Philosophy, 28 January 2008. Available online: http://www.cbs.columbia.edu/cscp/robhogendoorn/ (accessed on 3 May 2014).

21. Lutz, Antoine, Julie Brefczynski-Lewis, Tom Johnstone, and Richard J. Davidson. "Regulation of the Neural Circuitry of Emotion by Compassion Meditation: Effects of Meditative Expertise." PLoS ONE 3 (2008): e1897.

22. Garfield, Jay. "Ask Not What Buddhism Can Do for Cognitive Science: Ask What Cognitive Science Can Do for Buddhism.” Bulletin of Tibetology (Gangtok) 47 (2011): 15-30.

23. Van Beek, Martijn. "Unsettling the Cerebral Subject: Mind, Life, and the Politics of Meditation." Buddhism and Modernity: Global Dynamics of Transmission and Translation, Aarhus University, Aarhus, Denmark, 31 October-2 November 2013.

24. Chen, Ingfei. "Hidden Depths." New Scientist 2939 (2013): 33-37.

25. Choudhury, Suparna, and Jan Slaby, eds. Critical Neuroscience: A Handbook of the Social and Cultural Contexts of Neuroscience. Chichester: Wiley-Blackwell, 2012.

26. Wallace, B. Alan. The Taboo of Subjectivity: Toward a New Science of Consciousness. Oxford and New York: Oxford University Press, 2000.

27. Wallace, B. Alan. Contemplative Science: Where Buddhism and Neuroscience Converge. New York: Columbia University Press, 2007.

28. McGarrity, Andrew. "Buddhist Logic and Scientific Experimentation." Paper presented at Buddhism and Science: An International Workshop, University of Toronto, Scarborough, Canada, 12-14 April 2014. 
29. Robert H. Sharf. "Buddhist Modernism and the Rhetoric of Meditative Experience." Numen 42 (1995): 228-83.

30. Robert H. Sharf. "Experience.” In Critical Terms in Religious Studies. Edited by Mark C. Taylor. Chicago: The University of Chicago Press, 1998, pp. 94-116.

31. Thondup Rinpoche, Tulku. Hidden Teachings of Tibet: An Explanation of the Terma Tradition of the Nyingma School of Buddhism. London: Wisdom, 1986.

32. Janet Gyatso. Apparitions of the Self: The Secret Autobiographies of a Tibetan Visionary. Princeton: Princeton University Press, 1998

33. Samuel, Geoffrey. Mind, Body and Culture: Anthropology and the Biological Interface. Cambridge and New York: Cambridge University Press, 1990.

34. Bloor, David. Knowledge and Social Imagery. London and New York: Routledge, 1976.

35. Latour, Bruno. We Have Never Been Modern. Translated by Catherine Porter. Cambridge, MA: Harvard University Press, 1993.

36. Haraway, Donna. Modest_Witness@Second_Millennium.FemaleMan @_Meets_OncoMouse: Feminism and Technoscience. New York and London: Routledge, 1997.

37. Martin, Emily. The Woman in the Body: A Cultural Analysis of Reproduction. Boston: Beacon Press, 1987.

38. Goldacre, Ben. Bad Pharma: How Drug Companies Mislead Doctors and Harm Patients. New York: Faber and Faber, 2013.

39. Healy, David. Pharmageddon. Berkeley: University of California Press, 2012.

40. Munevar, Gonzalo. Knowledge. Indianapolis: Hackett Publishing, 1981.

41. Munevar, Gonzalo. "Towards a Future Epistemology of Science.” Explorations in Knowledge 1 (1984): 1-17.

42. Biernacki, Loriliai. "A Cognitive Science view of Abhinavagupta's Understanding of Consciousness." Paper presented at Buddhism and Science: An International Workshop, University of Toronto, Scarborough, Canada, 12-14 April 2014.

43. Hayes, Glen. "Possible Selves, Body Schemas, and Sädhana: Using Cognitive Science and Neuroscience in the Study of Medieval Vaișnava Sahajiyā Hindu Tantric Texts.” Paper presented at Buddhism and Science: An International Workshop, University of Toronto, Scarborough, Canada, 12-14 April 2014.

44. Mayor, David, and Mark S. Micozzi. Energy Medicine East and West: A Natural History of Qi. Edinburgh, London and New York: Churchill Livingstone, 2011.

45. Maturana, Humberto R., and Francisco J. Varela. Autopoesis and Cognition: The Realization of the Living. Dordrecht, Boston and London: D. Reidel, 1980.

46. Bateson, Gregory. Steps to an Ecology of Mind: Collected Essays in Anthropology, Psychiatry, Evolution and Epistemology. Frogmore: Paladin, 1973.

47. Thompson, Evan. Mind in Life: Biology, Phenomenology and the Sciences of Mind. Cambridge, MA and London: The Belknap Press of Harvard University Press, 2007.

48. Rose, Steven. "The Need for a Critical Neuroscience: From Neuroideology to Neurotechnology." In Critical Neuroscience: A Handbook of the Social and Cultural Contexts of Neuroscience. Edited by Suparna Choudhury and Jan Slaby. Oxford: Blackwell, 2012, pp. 53-66. 
49. Martin, Emily. "Talking Back to Neuroreductionism." In Cultural Bodies: Ethnography and Theory. Edited by Helen Thomas and Jamilah Ahmed. Oxford: Blackwell, 2004, pp. 190-211.

50. Waldron, William. "Buddhist Steps to an Ecology of Mind: Thinking about 'Thoughts without a Thinker'." Eastern Buddhist 34 (2002): pp. 1-52.

51. Varela, Francisco J., and Natalie Depraz. "Imagining: Embodiment, Phenomenology, and Transformation." In Buddhism and Science: Breaking New Ground. Edited by B. Alan Wallace. New York: Columbia University Press, 2003, pp. 195-230.

52. Samuel, Geoffrey. "Healing, Efficacy and the Spirits." Journal of Ritual Studies 24 (2010): 7-20.

53. Samuel, Geoffrey. "Amitāyus and the Development of Tantric Practices for Longevity and Health in Tibet." In Transformations and Transfer of Tantra in Asia and Beyond. Edited by István Keul. Berlin and New York: Walter de Gruyter, 2012, pp. 263-86.

54. Samuel, Geoffrey. "Panentheism and the Longevity Practices of Tibetan Buddhism." In Panentheism across the World's Traditions. Edited by Loriliai Biernacki and Philip Clayton. New York: Oxford University Press, 2013, pp. 83-99.

(C) 2014 by the author; licensee MDPI, Basel, Switzerland. This article is an open access article distributed under the terms and conditions of the Creative Commons Attribution license (http://creativecommons.org/licenses/by/3.0/). 